\title{
The epidermal growth factor tyrosine kinase inhibitor AG1478 and erlotinib reverse ABCG2-mediated drug resistance
}

\author{
ZHI SHI ${ }^{1,2}$, SMITABEN PARMAR ${ }^{1}$, XING-XIANG PENG ${ }^{1}$, TONG SHEN ${ }^{1}$, ROBERT W. ROBEY ${ }^{3}$, \\ SUSAN E. BATES ${ }^{3}$, LI-WU FU ${ }^{2}$, YINING SHAO ${ }^{1}$, YANG-MIN CHEN ${ }^{1}$, \\ FEIYANG ZANG ${ }^{1}$ and ZHE-SHENG $\mathrm{CHEN}^{1}$ \\ ${ }^{1}$ Department of Pharmaceutical Sciences, College of Pharmacy and Allied Health Professions, \\ St. John's University, Jamaica, NY 11439, USA; ${ }^{2}$ State Key Laboratory for Oncology in South China, \\ Cancer Center, Sun Yat-Sen University, Guangzhou 510060, P.R. China; ${ }^{3}$ Medical Oncology Branch, \\ Center for Cancer Research, National Cancer Institute, NIH, Bethesda, MD 20892-4256, USA
}

Received April 3, 2008; Accepted October 10, 2008

DOI: $10.3892 /$ or_00000248

\begin{abstract}
ABCG2 is an important member of ATP-binding cassette $(\mathrm{ABC})$ transporter shown to confer drug resistance in cancer cells. Recent studies show that an epidermal growth factor receptor (EGFR) tyrosine kinase inhibitor (TKI), gefitinib, is able to modulate the function of ABCG2 and reverse $\mathrm{ABCG}$ 2-mediated multidrug resistance (MDR) in cancer cells. Additionally, ABCG2 expression has been shown to impact treatment efficacy and development of sideeffects in patients receiving gefitinib. However, it is unclear whether other EGFR TKIs interact with ABCG2 in a similar manner. In the present study, we investigated the interaction of two other EGFR TKIs, AG1478 and erlotinib, with ABCG2. Our data show that AG1478 and erlotinib potently sensitized drug-resistant cells overexpressing either wild-type or mutated $\mathrm{ABCG} 2$ to the $\mathrm{ABCG} 2$ substrate anti-cancer drugs flavopiridol and mitoxantrone. Neither AG1478 nor erlotinib sensitized ABCG2-overexpressing cells to drugs that are not substrates of ABCG2 nor did they impact drug sensitivity of parental cells. Furthermore, AG1478 and erlotinib were able to significantly enhance the intracellular accumulation of mitoxantrone in cells expressing either wildtype or mutated ABCG2. Additionally, they did not alter the protein expression of ABCG2 in the ABCG2-overexpressing cells. Taken together, we conclude that AG1478 and erlotinib
\end{abstract}

Correspondence to: Dr Zhe-Sheng Chen, Department of Pharmaceutical Sciences, St. John's University, Jamaica, NY 11439, USA E-mail: chenz@stjohns.edu

Abbreviations: MDR, multidrug resistance; ABC, ATP-binding cassette; ABCG2, also called BCRP (breast cancer resistance protein)/MXR (mitoxantrone resistance protein); EGFR, epidermal growth factor receptor; TKI, tyrosine kinase inhibitor; FTC, fumitremorgin $\mathrm{C}$

Key words: multidrug resistance, ABCG2, AG1478, erlotinib potently reverse $\mathrm{ABCG} 2-$ mediated MDR through directly inhibiting the drug efflux function of ABCG2 in the ABCG2overexpressing cells. These results will be useful in the development of novel and more effective EGFR TKIs as well as the development of combinational chemotherapeutic strategies.

\section{Introduction}

ABCG2 (BCRP/MXR/ABCP) is a recently identified ATPbinding cassette $(\mathrm{ABC})$ transporter cloned from atypical multidrug-resistant MCF-7 human breast cancer cells selected with doxorubicin and verapamil (MCF-7/AdrVp) that displayed an ATP-dependent reduction in the intracellular accumulation of anthracyclines despite the absence of overexpression of ABCB1 (P-glycoprotein/P-gp/MDR1) or ABCC1 (MRP1) (1). Unlike ABCB1 and ABCC1, ABCG2 is as a half-transporter which forms a homodimer or multimer for transport activity (2). The spectrum of ABCG2 substrates is quite wide and includes anticancer drugs (anthracyclines, mitoxantrone, camptothecins, methotrexate and flavopiridol), nucleoside drugs (lamivudine and zidovudine) as well as natural compounds flavonoids, porphyrins and sulfated estrogens (3). The tissue distribution of ABCG2 is very extensive and there is considerable overlap with that of $\mathrm{ABCB} 1$ with $\mathrm{ABCG} 2$ expression mainly located in the placenta, blood-brain barrier, liver and intestinal tract (4). Additionally, ABCG2 was found to be the molecular determinant of the SP or 'side-population' phenotype in SP cells derived from bone marrow, muscle, pancreas, brain and embryonic stem cells, and may play a role in maintaining progenitor cells in an undifferentiated state by protecting them from exogenous and endogenous toxins (5). In the clinic, the distribution of ABCG2 to MDR disease in patients is still under study. Some groups have reported expression of $\mathrm{ABCG} 2$ in leukemia and some solid tumors and ABCG2 has been linked to treatment efficacy in acute myelogenous leukemia (AML). However, larger studies are still needed to elucidate the contribution of ABCG2 to clinical drug resistance (6). 
Theoretically, in disease where ABCG2 is overexpressed, inhibition of ABCG2 may be a viable therapeutic strategy to cancer patients, as ABCG2 inhibition can result in increased intracellular levels of anticancer drugs thereby increased cytotoxicity. In addition, the increased bioavailability of ABCG2 substrate drugs in the abcg2 knockout mice suggests that inhibition of $\mathrm{ABCG} 2$ function in vivo would increase systemic levels of anticancer drugs (7). Currently, the development of ABCG2 inhibitors is growing rapidly. The first reported inhibitor of ABCG2 was Fumitremorgin C (FTC) (8), a diketopiperazine isolated from the fermentation broth of Aspergillus fumigatus. Its clinical use has been limited by the neurotoxicity of FTC, however, another specific ABCG2 inhibitor, the FTC analogue Ko143, appears nontoxic in vitro at useful concentrations and displayed no signs of neurotoxicity in mice at high oral or i.p. doses (9). Several ABCB1 inhibitors have also been reported to inhibit ABCG2, such as cyclosporin A (10), elacridar (GF120918) (11), tariquidar (XR9576) (12) and biricodar (VX-710) (13). Interestingly, two novel target-directed small molecule anticancer clinical drugs, the Bcr-abl kinase inhibitor imatinib (STI 571/Gleevec) and the epidermal growth factor (EGFR) tyrosine kinase inhibitor (TKI) gefitinib (Iressa/ ZD1839), have been shown to inhibit the function of ABCG2 (14-19). Despite the fact that many ABCG2 inhibitors have been identified, none of them have been applied as a reversal agent in clinic.

In the present study, we investigated the effects of two EGFR TKIs, 4-(3-chloroanilino)-6,7-dimethoxyquinazoline (AG1478) and erlotinib (Tarceva/OSI-744) on ABCG2mediated MDR in cancer cells. Our results show that both AG1478 and erlotinib are able to potently reverse ABCG2mediated MDR in ABCG2-overexpressing cells, and increase the intracellular accumulation of mitoxantrone in these cells, but not affect the protein expression of ABCG2.

\section{Materials and methods}

Materials. $\left[{ }^{3} \mathrm{H}\right]$-mitoxantrone $(4 \mathrm{Ci} / \mathrm{mmol})$ was purchased from Moravek Biochemicals Inc (Brea, CA, USA). AntiABCG2 monoclonal antibody (BXP-34) was acquired from Signet Laboratories Inc. (Dedham, MA, USA). Anti-actin monoclonal antibody (sc-8432) was obtained from Santa Cruz Biotechnology Inc (Santa Cruz, CA, USA). AG1478 was purchased from A.G. Scientific, Inc. (San Diego, CA, USA). Erlotinib was kindly provided by ISO Pharmaceuticals (Melville, NY, USA). Fumitremorgin C (FTC) was synthesized by Thomas McCloud Developmental Therapeutics Program, Natural Products Extraction Laboratory, NCI, NIH (Bethesda, MD, USA). Other chemicals were purchased from Sigma Chemical Co (St. Louis, MO, USA).

Cell lines and culture. The wild-type ABCG2 [arginine (R) at 482 position]-overexpressing drug-resistant breast cancer cell line MCF-7/FLV1000 was maintained with $1000 \mathrm{nM}$ of flavopiridol (20). The mutated ABCG2 [arginine (R) $\rightarrow$ threonine $(\mathrm{T})$ at amino acid 482 position]-overexpressing drug-resistant breast cancer cell line MCF-7/ AdVp3000 was maintained in the medium with $5 \mu \mathrm{g} / \mathrm{ml}$ of verapamil and $3000 \mathrm{ng} / \mathrm{ml}$ of doxorubicin (20). Another mutant ABCG2

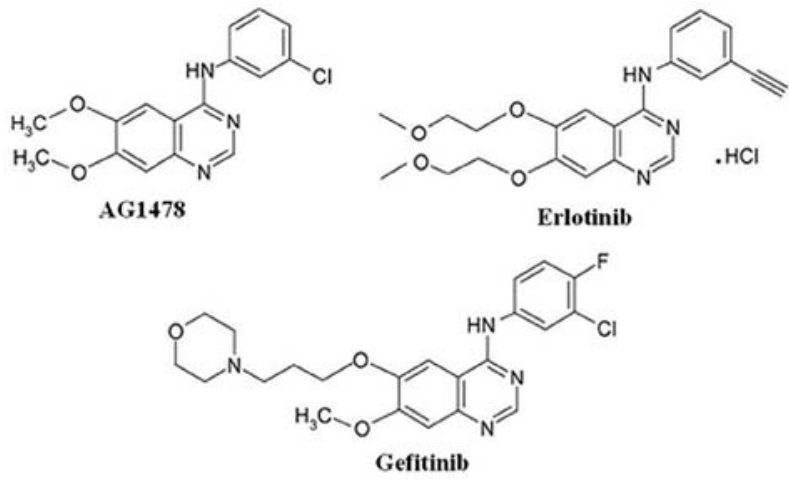

Figure 1. The chemical structures of AG1478, erlotinib and gefitinib.

[arginine $(\mathrm{R}) \rightarrow$ glycine $(\mathrm{G})$ at amino acid 482 position]overexpressing drug-resistant colon carcinoma cell line, S1M1-80, is cultivated in the medium with $80 \mu \mathrm{M}$ of mitoxantrone (20). The flavopiridol-resistant cell line S1/FLV5000, which does not express ABCG2, was also generated from $\mathrm{S} 1$ colon cancer cells by increasing exposing concentrations of flavopiridol and is maintained in the medium with $5000 \mathrm{nM}$ of flavopiridol (Robert W. Robey and Susan E. Bates, unpublished data). All the cell lines were grown as adherent monolayer in flasks with DMEM culture medium (Hyclone Co., UT, USA) containing $10 \%$ bovine serum at $37^{\circ} \mathrm{C}$ in a humidified atmo-sphere of $5 \% \mathrm{CO}_{2}$.

Western blot analysis. The methods of cell lysates preparation and Western blotting for ABCG2 was described in our previous study (21). The protein expression was quantified by Scion Image software (Scion Co., USA) (22).

MTT cytotoxicity assay. Cells were harvested with trypsin and resuspended in medium to a final concentration of $7.5 \times 10^{4}$ cells $/ \mathrm{ml}$ medium. Aliquot $(160 \mu 1)$ for each cell suspension were distributed evenly into 96-well multiplates. For reversal experiments, different concentrations of chemotherapeutic drugs $(20 \mu \mathrm{l} /$ well $)$ were added into designated wells after AG1478, erlotinib or FTC ( $20 \mu 1 /$ well) was added. After 68 h, $20 \mu 1$ of 3-(4,5-dimethylthiazol-2yl)-2,5-diphenyl tetrazolium bromide (MTT) solution $(4 \mathrm{mg} / \mathrm{ml})$ was added to each well, and the plate was further incubated for $4 \mathrm{~h}$, allowing viable cells to change the yellow MTT into darkblue formazan crystals. Subsequently the medium was discarded, and $100 \mu 1$ of dimethylsulfoxide (DMSO) was added into each well to dissolve the formazan crystals. The absorbance in individual well was determined at $570 \mathrm{~nm}$ by an OPSYS microplate Reader from DYNEX Technologies, Inc (Chantilly, VA, USA). The concentrations required to inhibit growth by $50 \%\left(\mathrm{IC}_{50}\right)$ were calculated from survival curves using the Bliss method (23).

Mitoxantrone accumulation. To determine the effect of AG1478 and erlotinib on the intracellular accumulations of $\left[{ }^{3} \mathrm{H}\right]$-mitoxantrone confluent cells in 24 -well plates were preincubated with or without the reversing agents for $1 \mathrm{~h}$ at $37^{\circ} \mathrm{C}$. Cells were then incubated with $0.2 \mu \mathrm{M}\left[{ }^{3} \mathrm{H}\right]$-mitoxantrone 
for $2 \mathrm{~h}$ in the presence or absence of the reversing agents at $37^{\circ} \mathrm{C}$. After washing 3 times with ice-cold PBS, the cells

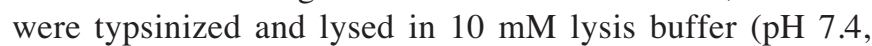
containing $1 \%$ Triton X-100 and $0.2 \%$ SDS). Each sample was placed in scintillation fluid and radioactivity was measured in a Packard TRI-CARB ${ }^{\circledR} 1900$ CA liquid scintillation analyzer from Packard Instrument Company, Inc (Downers Grove, IL, USA).

Statistical analysis. All experiments were repeated at least 2-3 times and the significantly differences were determined by using the Student's t-test at $\mathrm{p}<0.05$.

\section{Results}

AG1478 and erlotinib sensitize ABCG2-overexpressing cells to chemotherapeutic drugs. AG1478 and erlotinib share the same structural quinazoline backbone with gefitinib (Fig. 1), and it has been shown that gefitinib is able to inhibit the function of ABCG2 and reverse ABCG2-mediated MDR in vitro and in vivo $(5,15,19,24,25)$. Whether AG1478 and erlotinib have a similar effect as gefitinib on ABCG2 function is still unknown. To answer this question, we examined the effect of AG1478 and erlotinib on the sensitivity of ABCG2-overexpressing cancer cells to drugs that are substrates of ABCG2. Since mutations at amino acid 482 of ABCG2 could alter the substrate and antagonist specificity of ABCG2 (26,27), we examined the potential impact of mutation at this site on the effects of AG1478 and erlotinib by performing studies on cells overexpressing wildtype (R482) ABCG2-overexpressing MCF-7/FLV1000, mutant ABCG2-overexpressing MCF-7/AdVp3000 (R482T) and S1-M1-80 (R482G). As shown in Fig. 2A and B, ABCG2 was only overexpressed in MCF-7/FLV1000, MCF-7/ AdVp3000 and S1-M1-80, but not in the parental cells MCF-7 and S1 nor in the flavopiridol-resistant subline S1/FLV5000. Surprisingly, when we examined the sensitivity of all these cells to AG1478 and erlotinib, the results of MTT assay showed that AG1478 and erlotinib did not affect the growth of these cells even at concentrations up to $50 \mu \mathrm{M}$. Next, we examined whether AG1478 and erlotinib could sensitize the drug resistant cells to chemotherapeutic drugs. As shown in Table I, compared to parental MCF-7 cells, MCF-7/FLV1000 and MCF-7/AdVp3000 cells exhibited high levels of resistance to flavopiridol and mitoxantrone, but not to cisplatin, which is not a substrate of ABCG2. Similarly, the $\mathrm{IC}_{50}$ values for flavopiridol and mitoxantrone in S1-M1-80 were significantly higher than those in parental S1 cells. Interestingly, S1/FLV5000 cells displayed high levels of resistance to flavopiridol but relatively low levels of resistance to mitoxantrone and cisplatin. When cytotoxicity assays were repeated in the presence of the TKIs, AG1478 and erlotinib even at $2.5 \mu \mathrm{M}$ was able to decrease the $\mathrm{IC}_{50}$ values for flavopiridol and mitoxantrone in cells expressing wild-type or mutant ABCG2. At a concentration of $10 \mu \mathrm{M}, \mathrm{AG} 1478$ and erlotinib further decreased $\mathrm{IC}_{50}$ values for $\mathrm{ABCG} 2$ substrate drugs in the ABCG2-expressing cell lines down to levels that were observed when cytotoxicity assays were performed in the presence of the known specific ABCG2 inhibitor FTC at $2.5 \mu \mathrm{M}$. However, the $\mathrm{IC}_{50}$ values of these
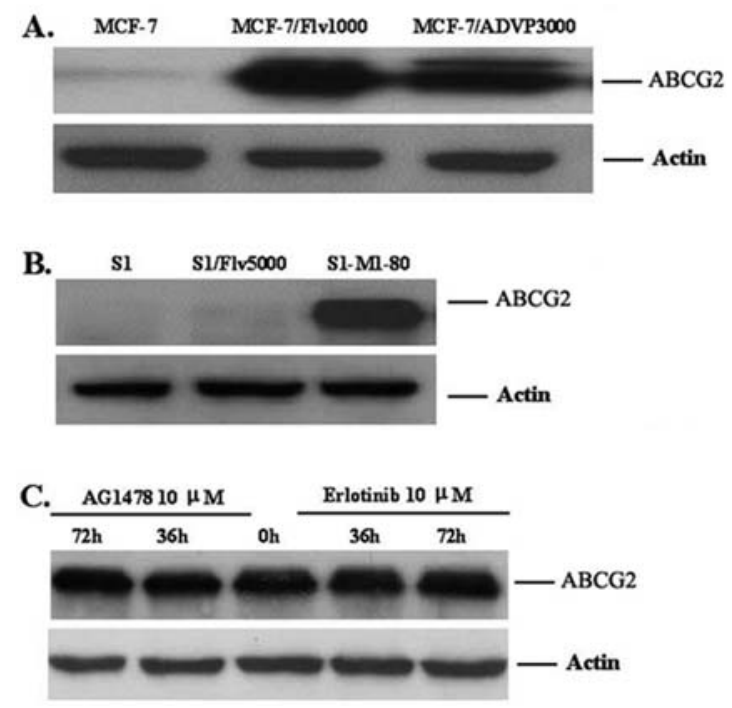

Figure 2. (A) The expression of ABCG2 in drug-selected cells. Cell lysates were prepared as described in Materials and methods. Equal amounts $(50 \mu \mathrm{g}$ protein) of cell lysates were used for each sample, subjected to SDS-PAGE and transferred to PVDF membranes. Membranes were subsequently probed with the BXP-21 antibody as outlined in Materials and methods (B) Effect of AG1478 and erlotinib on the expression of ABCG2 in MCF-7/FLV1000. MCF-7/FLV1000 cells were treated with $10 \mu \mathrm{M}$ AG1478 and erlotinib for 36 or $72 \mathrm{~h}$ and cell lysates were then prepared as in (A). Equal amounts (50 $\mu \mathrm{g}$ protein) of total cell lysates were used for each sample. All samples were separated by SDS-PAGE, and then transferred onto PVDF membrane. The membranes were immunoblotted with primary antibodies against ABCG2 or actin at a 1:200 dilution at $4^{\circ} \mathrm{C}$ overnight, then incubated with HRP-conjugated secondary antibody at a 1:1000 dilution at $4^{\circ} \mathrm{C}$ overnight. The protein-antibody complex was detected by chemoluminescence. Results from a representative experiment are shown. Similar results were obtained in two other independent experiments.

ABCG2 substarte drugs showed no significant difference in the parental cells or the S1/FLV5000 cells in the presence or absence of AG1478 or erlotinib. Furthermore, when the non-ABCG2 substrate drug cisplatin was used, its $\mathrm{IC}_{50}$ values were not affected by either AG1478, erlotinib or FTC in any of the cell lines. The data as a whole seem to suggest that the reversing effects of AG1478 and erlotinib were almost equal on ABCG2-mediated MDR. The representative cell survival curves are shown in Fig. 3, and demonstrate that the survival curves in the presence of AG1478 or erlotinib were remarkably shifted to the left in ABCG2-overexpressing cells. Based on the above results, it appears that AG1478 and erlotinib specifically sensitize ABCG2 overexpressing cells to chemotherapeutic drugs that are the substrates of ABCG2, however, they appear to be less potent than FTC.

$A G 1478$ and erlotinib increase the intracellular accumulation of $\left[{ }^{3} \mathrm{H}\right]$-mitoxantrone in $A B C G 2$ overexpressing cells. To investigate the mechanism by which AG1478 and erlotinib potentiate the sensitivity of ABCG2 overexpressing cells to chemotherapeutic drugs that are ABCG2 substrates, we examined the effect of AG1478 and erlotinib on the accumulation of $\left[{ }^{3} \mathrm{H}\right]$-mitoxantrone in the cells. Intracellular accumulation of $\left[{ }^{3} \mathrm{H}\right]$-mitoxantrone was measured in cells in the presence or absence of AG1478 or erlotinib, and the results are shown in Fig. 4. Intracellular accumulation of 


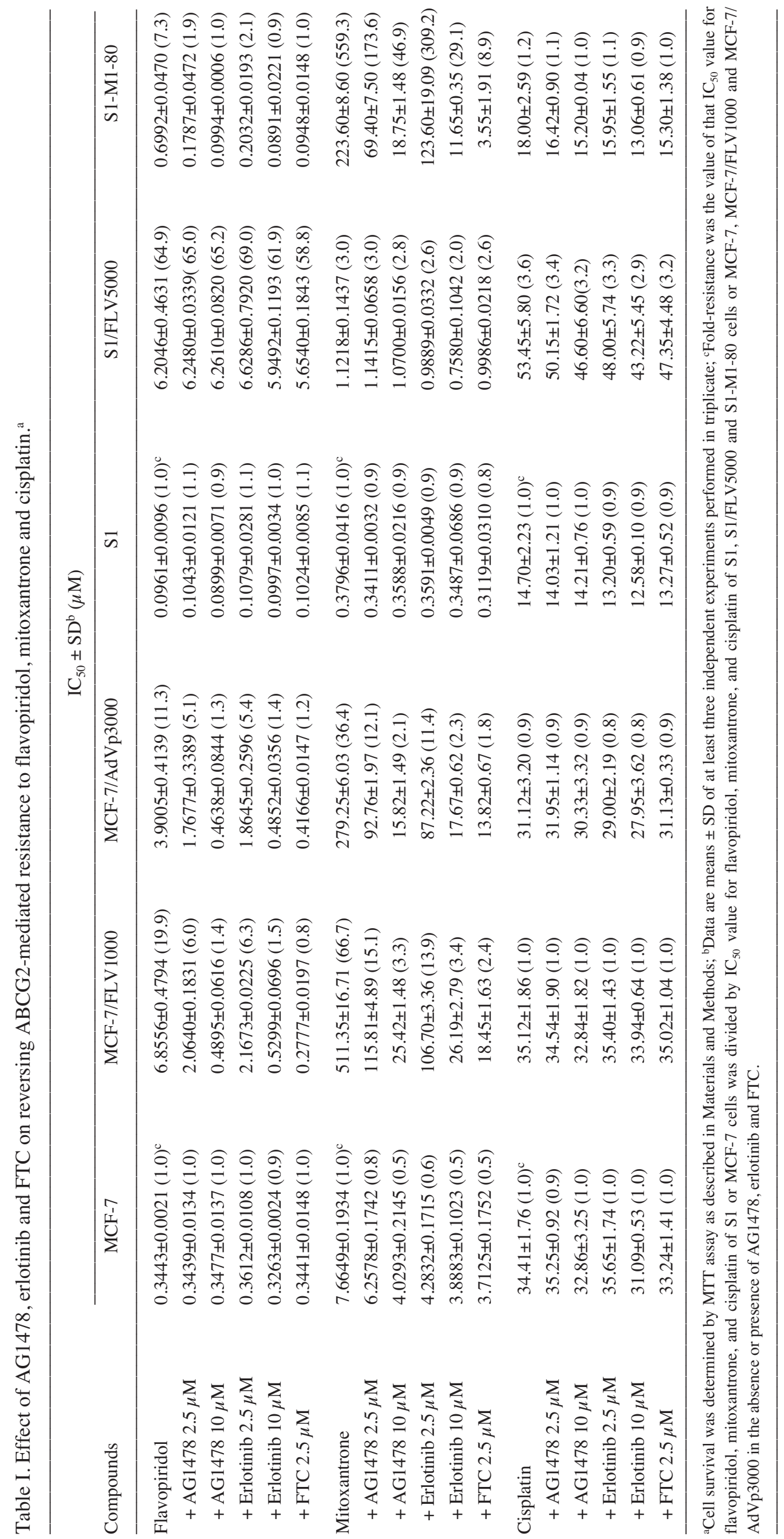



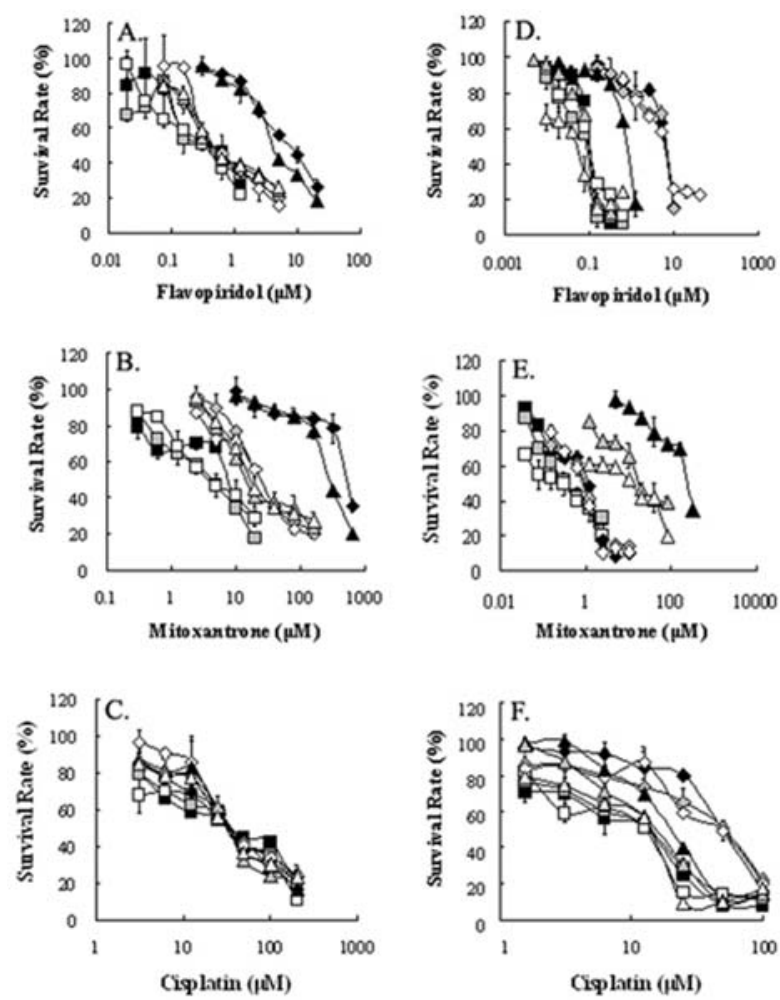

Figure 3. AG1478 and erlotinib reverse ABCG2-mediated drug resistance in ABCG2-overexpressing drug selected cells. Panels A, B and C: the survival curves of MCF-7 (closed squares), MCF-7/FLV1000 (closed rhombi) and MCF-7/AdVp3000 (closed triangles) cells at the different concentrations of flavopiridol, mitoxantrone, and cisplatin, and in the presence of AG1478 (gray symbols) or erlotinib (open symbols) at $10 \mu \mathrm{M}$. Panels D, E and F: the survival curves of S1 (closed squares), S1/FLV5000 (closed rhombi) and S1-M1-80 (closed triangles) cells at the different concentrations of flavopiridol, mitoxantrone, and cisplatin, respectively, and in the presence of AG1478 (gray symbols) or erlotinib (open symbols) at $10 \mu \mathrm{M}$. Cell survival was determined by MTT assay as described in Materials and methods. Data points are the means \pm SD of triplicate determinations. At least 3 independent experiments were performed and a representative experiment is shown.

$\left[{ }^{3} \mathrm{H}\right]-$ mitoxantrone in MCF-7/FLV 1000 and MCF-7/ AdVp3000 cells were significantly less than that of parental MCF-7 cells, and less mitoxantrone accumulation was also observed in S1-M1-80 subline than in the parental S1 cells. Although exhibiting slight resistance to mitoxantrone, S1/FLV5000 cells had the similar intracellular $\left[{ }^{3} \mathrm{H}\right]-$ mitoxantrone levels compared to $\mathrm{S} 1$ cells. In the presence of AG1478 or erlotinib, either at $2.5 \mu \mathrm{M}$ or $10 \mu \mathrm{M}$, all ABCG2 overexpressing cell lines showed an increase in intracellular $\left[{ }^{3} \mathrm{H}\right]$-mitoxantrone levels, and this increase became more pronounced with increasing concentrations of AG1478 or erlotinib. AG1478 and erlotinib caused similar increase in intracellular mitoxantrone levels at $10 \mu \mathrm{M}$, and the increase were slightly less than that observed with FTC at $2.5 \mu \mathrm{M}$. In MCF-7, S1 and S1/FLV5000 cells, neither AG1478 nor erlotinib affected intracellular $\left[{ }^{3} \mathrm{H}\right]$-mitoxantrone levels. Taken together, these data suggest that AG1478 and erlotinib are able to directly inhibit the efflux function of ABCG2 resulting in the increase of the intracellular accumulation of $\left[{ }^{3} \mathrm{H}\right]$-mitoxantrone in the ABCG 2 overexpressing cells.

AG1478 and erlotinib do not affect expression levels of $A B C G 2$. Aside from directly inhibiting the pump activity of
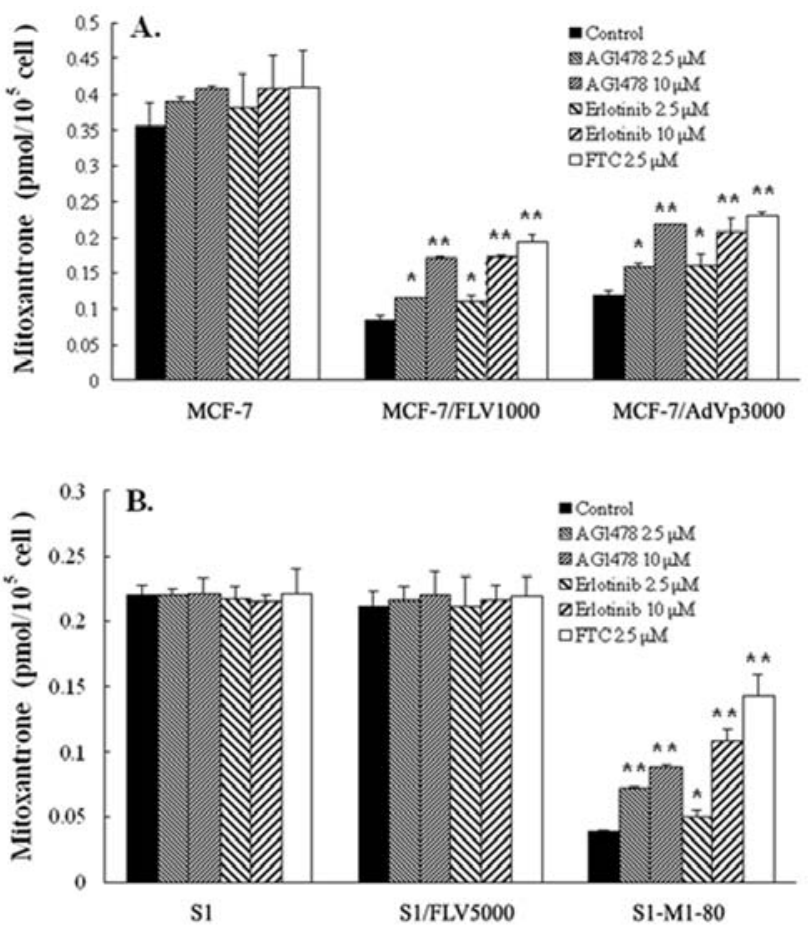

Figure 4. Effect of AG1478 and erlotinib on the accumulation of $\left[{ }^{3} \mathrm{H}\right]$ mitoxantrone. The accumulation of $\left[{ }^{3} \mathrm{H}\right]$-mitoxantrone (A and $\mathrm{B}$ ) was measured after cells were pre-incubated with or without AG1478, erlotinib or FTC for $1 \mathrm{~h}$ at $37^{\circ} \mathrm{C}$ and then incubated with $0.2 \mu \mathrm{M}\left[{ }^{3} \mathrm{H}\right]$-mitoxantrone for another $2 \mathrm{~h}$ at $37^{\circ} \mathrm{C}$. Data points represent the means $\pm \mathrm{SD}$ of triplicate determinations. ${ }^{*} \mathrm{p}<0.05$ and ${ }^{* *} \mathrm{p}<0.01$ for values vs. those in the control group. At least 3 independent experiments were performed and a representative experiment is shown.

ABCG2, decreasing the expression level of ABCG2 also can lead to the reversal of ABCG2-mediated MDR. To study the effect of AG1478 and erlotinib on the ABCG2 protein expression, MCF-7/FLV1000 cells were treated with AG1478 or erlotinib at $10 \mu \mathrm{M}$ for 36 or $72 \mathrm{~h}$, then lysed with RIPA buffer and analysed by Western blotting. As shown in Fig. 2B, the protein levels of ABCG2 in MCF-7/FLV1000 cells were unchanged after treatment with $10 \mu \mathrm{M}$ AG1478 or erlotinib for 36 and $72 \mathrm{~h}$. This result suggests that AG1478 and erlotinib do not affect the levels of protein expression of $\mathrm{ABCG} 2$ in the ABCG2-overexpressing cells.

\section{Discussion}

Molecular targeting therapy for cancer treatment is a fastgrowing research field in oncology with considerable progress being made in understanding specific cellular, molecular and genetic mechanisms that contribute to cancer growth and progression. One specific molecular target of high promise in oncology is the EGFR pathway. EGFR is a key physiological regulator of growth and differentiation of normal epithelial cells, but it is also involved in the development and progression of cancers derived from these tissues $(28,29)$. EGFR is often overexpressed, dysregulated or mutated in many epithelial malignancies, and these abnormal alterations of EGFR activate a series of intracellular signaling pathways and play a central role in many of the processes involved in tumor growth and progression, such as prolifer- 
ation, angiogenesis, invasiveness, metastasis, decreased apoptosis, and loss of differentiation $(28,29)$. Consequently, EGFR has been proposed as a rational molecular target for anticaner strategies. Currently, two predominant classes of anti-EGFR targeting agents have been developed for use in the clinic including monoclonal antibodies such as cetuximab (Erbitux/C225) that blocks the ligand binding to the extracellular domain of EGFR and prevents receptor activation, and small molecule TKIs such as gefitinib and erlotinib that compete with ATP to bind to the intracellular receptor catalytic domain of EGFR $(30,31)$. During the clinical development of these compounds it becomes important to examine potential mechanisms of resistance, leading to the hypothesis that these compounds may interact with $\mathrm{ABC}$ transporters. Several groups have reported on the interaction between ABCG2 and EGFR TKIs such as CI1033 (PD 183805) and gefitinib (4,5,18,19,24,25,32).

In this study, we characterized the interaction of two other EGFR TKIs, AG1478 and erlotinib that have the same structural quinazoline backbone as gefitinib, with ABCG2. Our data show that AG1478 and erlotinib potently sensitized drug-selected cells expressing wild-type or mutant ABCG2 to the ABCG2 substrate anticancer drugs flavopiridol and mitoxantrone. However, AG1478 and erlotinib did not sensitize cells to the non-ABCG2 substrates drug cisplatin and have no effect on the sensitivity of the parental cells or the drug-resistant cells that did not overexpress ABCG2. These data suggest that AG1478 and erlotinib could effectively reverse ABCG2-mediated MDR, despite the fact that their potency was less than that of FTC. Furthermore, the results of drug accumulation study with $\left[{ }^{3} \mathrm{H}\right]$-mitoxantrone showed that AG1478 and erlotinib significantly enhanced the intracellular accumulation of mitoxantrone in cells expressing either wild-type or mutant ABCG2. Additionally, we examined the effect of AG1478 and erlotinib on the ABCG2 expression levels in drug-resistant cells and found that cells treated with $10 \mu \mathrm{M} \mathrm{AG1478}$ or erlotinib for up to $72 \mathrm{~h}$ displayed no alteration in expression of ABCG2, despite a previous report showing that AG1478 could abolish EGFmediated increases of ABCG2 expression at both mRNA and protein levels (33). Consequently, we infer that the mechanism by which AG1478 and erlotinib reverse ABCG2mediated MDR is by directly inhibiting its drug transport function. However, it should be noted that we only examined the drug-selected resistant cells for this study where multiple drug-resistance mechanisms can exist. Thus, further experiments are needed to confirm the effect of AG1478 and erlotinib on ABCG2-mediated MDR, possibly in a model system using ABCG2 cDNA-transfected cells. Taking into account previous reports with other quinazoline backbone EGFR TKIs, we can deduce that the interaction of these compounds with ABCG2 may be a class of effect. Hence, this interaction should be taken into consideration when developing other novel quinazoline EGFR TKIs in the future.

On the basis of the insights obtained thus far, ABCG2 function may be relevant in two aspects of cancer chemotherapy: i) ABCG2 may be endogenously expressed in cancer cells and therefore render these cancer cells resistant to chemotherapy; and ii) ABCG2 may be an important factor in the pharmacology of substrate anticancer drugs, affecting their oral bioavailability and plasma clearance (34). Although several reports have examined the expression of ABCG2 in various tumor tissues in an attempt to determine the role of ABCG2 in clinical drug resistance, the definitive answer will not be reached until larger, more extensive studies are carried out (6). The important role of ABCG2 in pharmacology suggests that the interaction of EGFR TKIs with ABCG2 should be considered as EGFR TKIs are used in the clinic. This is especially true in normal tissues where ABCG2 is highly expressed such as the GI tract and brain microvasculature where inhibition of ABCG2 may alter the pharmacokinetics of substrate compounds. Actually, it has been reported that pretreatment of $\mathrm{abcb} 1(\mathrm{a} / \mathrm{b})^{-/-}$mice with gefitinib increased oral absorption and decreased systemic clearance of topotecan (5). Coadministration of oral gefitinib with oral irinotecan in mice was shown to increase the oral bioavailability of irinotecan (24). Gefitinib was also found to increase the penetration of topotecan in mouse brain extracellular fluid suggesting that gefitinib inhibits efflux transporters such as ABCG2 at the blood-brain barrier (35).

Additionally, the disposition of EGFR TKIs may be affected by ABCG2 expression. One common singlenucleotide polymorphism of $\mathrm{ABCG} 2$ that has been shown to affect the function of ABCG2, Q141K (421C $\rightarrow$ A), was reported to be associated with gefitinib-induced diarrhea, resulting in a high risk of diarrhea in patients treated with oral gefitinib (36), and was also found to be associated with greater accumulation at steady-state and toxicity of gefitinib (37). Similar results may be observed for erlotinib since it has been found to be an ABCG2 substrate although additional studies are needed to verify this possibility.

In conclusion, the present study shows that AG1478 and erlotinib potently reverse ABCG2-mediated MDR by directly inhibiting their drug efflux function, resulting in the increase of the intracellular concentration of anticancer drugs in ABCG2 overexpressing cancer cells. Our results may be useful to develop new and more effective EGFR TKIs as well as new combinational chemotherapeutic strategies.

\section{Acknowledgements}

We thank OSI Pharmaceuticals (Melville, NY) for providing erlotinib. This work was supported by funds from St. John's University Tenure Track Faculty Start-Up Funding (No. C0531, Z.S. Chen) and Seed Grant of St. John's University (No. 579-1110, Z.S. Chen). Z. Shi is a recipient of Kaisi fellowship for overseas study at St. John's University from Sun Yat-Sen University. Yining Shao, Yang-Min Chen and Feiyang Zang are the summer research students from high schools.

\section{References}

1. Doyle LA and Ross DD: Multidrug resistance mediated by the breast cancer resistance protein BCRP (ABCG2). Oncogene 22: 7340-7358, 2003.

2. Kage K, Tsukahara S, Sugiyama T, Asada S, Ishikawa E, Tsuruo $T$ and Sugimoto $Y$ : Dominant-negative inhibition of breast cancer resistance protein as drug efflux pump through the inhibition of S-S dependent homodimerization. Int J Cancer 97: 626-630, 2002. 
3. Krishnamurthy P and Schuetz JD: Role of ABCG2/BCRP in biology and medicine. Annu Rev Pharmacol Toxicol 46: 381-410, 2006.

4. Erlichman C, Boerner SA, Hallgren CG, Spieker R, Wang XY, James CD, Scheffer GL, Maliepaard M, Ross DD, Bible KC and Kaufmann SH: The HER tyrosine kinase inhibitor CI1033 enhances cytotoxicity of 7-ethyl-10-hydroxycamptothecin and topotecan by inhibiting breast cancer resistance protein-mediated drug efflux. Cancer Res 61: 739-748, 2001.

5. Leggas M, Panetta JC, Zhuang Y, Schuetz JD, Johnston B Bai F, Sorrentino B, Zhou S, Houghton PJ and Stewart CF: Gefitinib modulates the function of multiple ATP-binding cassette transporters in vivo. Cancer Res 66: 4802-4807, 2006.

6. Robey RW, Polgar O, Deeken J, To KW and Bates SE: ABCG2: determining its relevance in clinical drug resistance. Cancer Metastasis Rev 26: 39-57, 2007

7. Zhou S, Morris JJ, Barnes Y, Lan L, Schuetz JD and Sorrentino BP: Bcrp1 gene expression is required for normal numbers of side population stem cells in mice, and confers relative protection to mitoxantrone in hematopoietic cells in vivo. Proc Natl Acad Sci USA 99: 12339-12344, 2002

8. Rabindran SK, He H, Singh M, Brown E, Collins KI, Annable T and Greenberger LM: Reversal of a novel multi-drug resistance mechanism in human colon carcinoma cells by fumitremorgin C. Cancer Res 58: 5850-5858, 1998.

9. Allen JD, van Loevezijn A, Lakhai JM, van der Valk M, van Tellingen O, Reid G, Schellens JH, Koomen GJ and Schinkel AH: Potent and specific inhibition of the breast cancer resistance protein multidrug transporter in vitro and in mouse intestine by a novel analogue of fumitremorgin $\mathrm{C}$. Mol Cancer Ther 1: 417-425, 2002

10. Qadir M, O'Loughlin KL, Fricke SM, Williamson NA, Greco WR, Minderman H and Baer MR: Cyclosporin A is a broad-spectrum multidrug resistance modulator. Clin Cancer Res 11:2320-2326, 2005.

11. de Bruin M, Miyake K, Litman T, Robey R and Bates SE: Reversal of resistance by GF120918 in cell lines expressing the ABC half-transporter, MXR. Cancer Lett 146: 117-126, 1999.

12. Robey RW, Steadman K, Polgar O, Morisaki K, Blayney M, Mistry P and Bates SE: Pheophorbide a is a specific probe for ABCG2 function and inhibition. Cancer Res 64: 1242-1246, 2004.

13. Minderman H, O'Loughlin KL, Pendyala L and Baer MR: VX710 (biricodar) increases drug retention and enhances chemosensitivity in resistant cells overexpressing P-glycoprotein, multidrug resistance protein, and breast cancer resistance protein. Clin Cancer Res 10: 1826-1834, 2004.

14. Burger H, van Tol H, Boersma AW, Brok M, Wiemer EA, Stoter G and Nooter K: Imatinib mesylate (STI571) is a substrate for the breast cancer resistance protein (BCRP)/ABCG2 drug pump. Blood 104: 2940-2942, 2004.

15. Elkind NB, Szentpetery Z, Apati A, Ozvegy-Laczka C, Varady G, Ujhelly O, Szabo K, Homolya L, Varadi A, Buday L, Keri G, Nemet K and Sarkadi B: Multidrug transporter ABCG2 prevents tumor cell death induced by the epidermal growth factor receptor inhibitor Iressa (ZD1839, Gefitinib). Cancer Res 65: 1770-1777, 2005.

16. Houghton PJ, Germain GS, Harwood FC, Schuetz JD, Stewart CF, Buchdunger E and Traxler P: Imatinib mesylate is a potent inhibitor of the ABCG2 (BCRP) transporter and reverses resistance to topotecan and SN-38 in vitro. Cancer Res 64 2333-2337, 2004

17. Jordanides NE, Jorgensen HG, Holyoake TL and Mountford JC: Functional ABCG2 is overexpressed on primary CML CD $34^{+}$cells and is inhibited by imatinib mesylate. Blood 108: 1370-1373, 2006

18. Nakamura Y, Oka M, Soda H, Shiozawa K, Yoshikawa M, Itoh A, Ikegami Y, Tsurutani J, Nakatomi K, Kitazaki T, Doi S, Yoshida H and Kohno S: Gefitinib ('Iressa', ZD1839), an epidermal growth factor receptor tyrosine kinase inhibitor, reverses breast cancer resistance protein/ABCG2-mediated drug resistance. Cancer Res 65: 1541-1546, 2005.

19. Yanase K, Tsukahara S, Asada S, Ishikawa E, Imai Y and Sugimoto Y: Gefitinib reverses breast cancer resistance proteinmediated drug resistance. Mol Cancer Ther 3: 1119-1125, 2004.

20. Robey RW, Medina-Perez WY, Nishiyama K, Lahusen T, Miyake K, Litman T, Senderowicz AM, Ross DD and Bates SE: Overexpression of the ATP-binding cassette half-transporter, ABCG2 (Mxr/BCrp/ABCP1), in flavopiridol-resistant human breast cancer cells. Clin Cancer Res 7: 145-152, 2001.
21. Shi Z, Jain S, Kim IW, Peng XX, Abraham I, Youssef DT, Fu LW, El Sayed K, Ambudkar SV and Chen ZS: Sipholenol A, a marine-derived sipholane triterpene, potently reverses Pglycoprotein (ABCB1)-mediated multidrug resistance in cancer cells. Cancer Sci 98: 1373-1380, 2007.

22. Shi Z, Liang YJ, Chen ZS, Wang XH, Ding Y, Chen LM and Fu LW: Overexpression of Survivin and XIAP in MDR cancer cells unrelated to P-glycoprotein. Oncol Rep 17: 969-976, 2007.

23. Shi Z, Liang YJ, Chen ZS, Wang XW, Wang XH, Ding Y, Chen LM, Yang XP and Fu LW: Reversal of MDR1/P-glycoprotein-mediated multidrug resistance by vector-based RNA interference in vitro and in vivo. Cancer Biol Ther 5: 39-47, 2006.

24. Stewart CF, Leggas M, Schuetz JD, Panetta JC, Cheshire PJ, Peterson J, Daw N, Jenkins JJ III, Gilbertson R, Germain GS, Harwood FC and Houghton PJ: Gefitinib enhances the antitumor activity and oral bioavailability of irinotecan in mice. Cancer Res 64: 7491-7499, 2004.

25. Yang CH, Huang CJ, Yang CS, Chu YC, Cheng AL, Whang-Peng J and Yang PC: Gefitinib reverses chemotherapy resistance in gefitinib-insensitive multidrug resistant cancer cells expressing ATP-binding cassette family protein. Cancer Res 65: 6943-6949, 2005.

26. Honjo Y, Hrycyna CA, Yan QW, Medina-Perez WY, Robey RW, van de Laar A, Litman T, Dean M and Bates SE: Acquired mutations in the MXR/BCRP/ABCP gene alter substrate specificity in MXR/BCRP/ABCP-overexpressing cells. Cancer Res 61: 6635-6639, 2001

27. Robey RW, Honjo Y, Morisaki K, Nadjem TA, Runge S, Risbood M, Poruchynsky MS and Bates SE: Mutations at amino-acid 482 in the ABCG2 gene affect substrate and antagonist specificity. Br J Cancer 89: 1971-1978, 2003.

28. Grant S, Qiao L and Dent P: Roles of ERBB family receptor tyrosine kinases, and downstream signaling pathways, in the control of cell growth and survival. Front Biosci 7: D376-D389, 2002.

29. Normanno N, De Luca A, Bianco C, Strizzi L, Mancino M, Maiello MR, Carotenuto A, De Feo G, Caponigro F and Salomon DS: Epidermal growth factor receptor (EGFR) signaling in cancer. Gene 366: 2-16, 2006.

30. Cascone T, Morelli MP and Ciardiello F: Small molecule epidermal growth factor receptor (EGFR) tyrosine kinase inhibitors in non-small cell lung cancer. Ann Oncol 17 (Suppl 2): 46-48, 2006.

31. Grunwald V and Hidalgo M: Developing inhibitors of the epidermal growth factor receptor for cancer treatment. J Natl Cancer Inst 95: 851-867, 2003

32. Kitazaki T, Oka M, Nakamura Y, Tsurutani J, Doi S, Yasunaga M, Takemura M, Yabuuchi H, Soda H and Kohno S: Gefitinib, an EGFR tyrosine kinase inhibitor, directly inhibits the function of P-glycoprotein in multidrug resistant cancer cells. Lung Cancer 49: 337-343, 2005.

33. Meyer zu Schwabedissen HE, Grube M, Dreisbach A, Jedlitschky G, Meissner K, Linnemann K, Fusch C, Ritter CA, Volker U and Kroemer HK: Epidermal growth factor-mediated activation of the map kinase cascade results in altered expression and function of ABCG2 (BCRP). Drug Metab Dispos 34: 524-533, 2006.

34. Allen JD and Schinkel AH: Multidrug resistance and pharmacological protection mediated by the breast cancer resistance protein (BCRP/ABCG2). Mol Cancer Ther 1: 427-434, 2002.

35. Zhuang Y, Fraga CH, Hubbard KE, HagedornN, Panetta JC, Waters CM and Stewart CF: Topotecan central nervous system penetration is altered by a tyrosine kinase inhibitor. Cancer Res 66: 11305-11313, 2006.

36. Cusatis G, Gregorc V, Li J, Spreafico A, Ingersoll RG, Verweij J, Ludovini V, Villa E, Hidalgo M, Sparreboom A and Baker SD: Pharmacogenetics of ABCG2 and adverse reactions to gefitinib. J Natl Cancer Inst 98: 1739-1742, 2006.

37. Li J, Cusatis G, Brahmer J, Sparreboom A, Robey RW, Bates SE, Hidalgo $M$ and Baker SD: Association of variant ABCG2 and the pharmacokinetics of epidermal growth factor receptor tyrosine kinase inhibitors in cancer patients. Cancer Biol Ther 6: 432-438, 2007. 